\title{
Recent Trends and Advances in Cancer-Induced Bone Disease
}

\author{
Aymen I. Idris ${ }^{1}$
}

Received: 8 December 2017 / Accepted: 13 December 2017 / Published online: 16 January 2018

(c) Springer Science+Business Media, LLC, part of Springer Nature 2018

In recent years, cancer-induced bone disease (CIBD) has become an important area of research to many, and scientific research in this area has been growing within the bone research community. The source of this enthusiasm was the expectation that incidences of skeletal related events in cancer patients would increase, as cancer becomes a chronic disease. Furthermore, drug treatments that are available in clinical practice for advanced cancer patients are effective at slowing disease progression and its recurrence; however, bone metastasis, spread of primary bone cancer to distant organs and bone pain still remain serious clinical problems, and are often inadequately managed in patients.

In this special "cancer and bone" issue of Calcified Tissue International and Musculoskeletal Research journal, I assembled a collection of review articles that focus on "hot topics" in the field of CIBD. The reviews are intended for basic and clinical bone scientists with special interest in skeletal disorders associated with primary bone cancers and bone metastasis. All reviews have been written by experts in the field and are well researched. The list of authors also includes a group of early- and mid-career researchers working on the field of CIBD research. This blend offers special support to up-coming investigators and future leaders.

The special issue begins with a review article by Rucci and Teti that tackles the topic of "osteomimicry" and how this phenomenon influences the ability of metastatic cancer cells that originated in distant organs such as the breast and prostate to adapt to the skeleton, prosper and develop the ability to disrupt the function of native cells in the tumour microenvironment [1].

Osteolytic bone metastases are a common cause of morbidity in patients with advanced breast and prostate. And thus, the next two articles provide an extensive review of the hallmarks of secondary breast [2] and prostate [3] in bone,

Aymen I. Idris

aymen.idris@sheffield.ac.uk

1 Department of Oncology and Metabolism, University of Sheffield, Sheffield, UK and highlight current and future treatments for patients with CIBD caused by these cancers.

The mechanisms by which tumour cells metastasize to bone have eluded bone researchers for centuries. Furthermore, many of the factors and signalling pathways that have been implicated in this process remain unknown or their action is poorly understood. In this issue, Rumney and colleagues provide an insight into the role of hypoxia in the regulation of bone metastasis and summarise the key tumour- and bone-derived factors implicated in hypoxiainduced CIBD [4].

CIBD, bone pain and metastasis are serious complications in patients with primary bone tumours. To cover this topic, I included an article by Brown et al. that discusses the histological, molecular and genetic heterogeneity among bone sarcomas, with particular emphasis on osteosarcoma and Ewing sarcoma and chondrosarcoma [5]. The review also summarises the therapeutic advances in the field of primary bone cancer.

Multiple myeloma (MM) is another aggressive form of cancer, and CIBD and bone pain caused by MM cells are serious consequences of the disease. This issue contains an article that summarises the latest advances in the pathophysiology of MM and describes existing and new therapeutic approaches to manage this disease [6]. A second article on the same topic by Accardi et al. focuses on the latest research on the use of proteasome inhibitors for the management of MM-induced CIBD [7].

CIBD is one of the causes of mortality in cancer patients with advanced disease. Although advances in early detection and drug therapy have been effective in the reduction of skeletal complications associated with CIBD, improvement in survival and quality of life of patients still remain as major problems. This special issue concludes with two articles by Sousa and Clezardin [8] and Handforth et al. [9] that describe trends and advances on bone-targeted therapies in the treatment of CIBD, and summarise preclinical and clinical findings on preventive and curative therapies.

It has been a great pleasure to bring this unique set of review articles together into this special "bone and cancer" 
issue of Calcified Tissue International and Musculoskeletal Research journal. I very much hope that the readers of the journal will find the articles in this issue as informative and enjoyable to read.

\section{References}

1. Rucci N, Teti A (2017) Osteomimicry: how the seed grows in the soil. Calcif Tissue Int. https://doi.org/10.1007/s00223-017-0365-1

2. Johnson RW, Suva LJ (2017) Hallmarks of bone metastasis. Calcif Tissue Int. https://doi.org/10.1007/s00223-017-0362-4

3. Park SH, Keller ET, Shiozawa Y (2017) Bone marrow microenvironment as a regulator and therapeutic target for prostate cancer bone metastasis. Calcif Tissue Int. https://doi.org/10.1007/ s00223-017-0350-8

4. Cox TR, Erler JT, Rumney RMH (2017) Established models and new paradigms for hypoxia-driven cancer-associated bone disease. Calcif Tissue Int. https://doi.org/10.1007/s00223-017-0352-6
5. Brown HK, Schiavone K, Gouin F, Heymann M-F, Heymann D (2017) Biology of bone sarcomas and new therapeutic developments. Calcif Tissue Int. https://doi.org/10.1007/ s00223-017-0372-2

6. Ring ES, Lawson MA, Snowden JA, Jolley I, Chantry AD (2017) New agents in the treatment of myeloma bone disease. Calcif Tissue Int. https://doi.org/10.1007/s00223-017-0351-7

7. Accardi F, Toscani D, Costa F, Aversa F, Giuliani N (2017) The proteasome and myeloma-associated bone disease. Calcif Tissue Int. https://doi.org/10.1007/s00223-017-0349-1

8. Sousa S, Clezardin P (2017) Bone-targeted therapies in cancerinduced bone disease. Calcif Tissue Int. https://doi.org/10.1007/ s00223-017-0353-5

9. Handforth C, D’Oronzo S, Coleman R, Brown J (2017) Cancer treatment and bone health. Calcif Tissue Int. https://doi. org/10.1007/s00223-017-0369-x 